\title{
Influence of Polymer Blending of Cellulose Acetate Butyrate for $\mathrm{CO}_{2} / \mathrm{N}_{2}$ Separation
}

\author{
Shi Chin Ng, ${ }^{1}$ Zeinab Abbas Jawad, ${ }^{1 *}$ Peng Chee Tan, ${ }^{2}$ Bridgid Lai Fui Chin ${ }^{1}$ \\ and Ren Jie Lee ${ }^{1}$ \\ ${ }^{1}$ Department of Chemical Engineering, Faculty of Engineering and Science, \\ Curtin University Malaysia, 98009 Sarawak, Malaysia \\ ${ }^{2}$ School of Energy and Chemical Engineering, Xiamen University Malaysia, \\ Jalan Sunsuria, Bandar Sunsuria, 43900 Sepang, Selangor, Malaysia \\ *Corresponding author: zeinab.aj@curtin.edu.my
}

Published online: 25 April 2020

To cite this article: $\mathrm{Ng}, \mathrm{S}$. C. et al. (2020). Influence of polymer blending of cellulose acetate butyrate for $\mathrm{CO}_{2} / \mathrm{N}_{2}$ separation. J. Phys. Sci., 31(1), 69-84. https://doi.org/10.21315/ jps2020.31.1.5

To link to this article: https://doi.org/10.21315/jps2020.31.1.5

\begin{abstract}
In recent years, carbon dioxide $\left(\mathrm{CO}_{2}\right)$ emission has increased significantly. To overcome this issue, carbon capture and storage was implemented to remove $\mathrm{CO}_{2}$ due to its low energy consumption and economic advantages. As a result, membrane technology was introduced as one of the technologies for $\mathrm{CO}_{2}$ separation to capture $\mathrm{CO}_{2}$ from industrial processes. Cellulose acetate butyrate (CAB) was selected as the material for polymeric membrane due to its high $\mathrm{CO}_{2}$ solubility. The $C A B$ membrane was fabricated by blending two $C A B$ polymers at different molecular weights of 70000 and 65000 using the wet-phase inversion method. A study of the parameter was carried out as it affected the structure and separation performance of the membrane in particular, polymer concentration. The results showed the satisfactory performance of CAB membrane blended with molecular weights of 70000 and 65000 at a ratio of 40:60 (M3) where, the $\mathrm{CO}_{2}$ permeance, nitrogen $\left(\mathrm{N}_{2}\right)$ permeance and $\mathrm{CO}_{2} / \mathrm{N}_{2}$ selectivity were 26.39 GPU, 7.73 GPU and 3.41 GPU, respectively. Hence, it is expected that this research may apply to membrane gas separation in industries such as power plants to separate $\mathrm{CO}_{2}$ from exhaust gas and reduce $\mathrm{CO}_{2}$ emissions.
\end{abstract}

Keywords: Cellulose acetate butyrate, gas separation, polymer concentration, polymer blending, membrane separation 


\section{INTRODUCTION}

In the 21st century, the carbon dioxide $\left(\mathrm{CO}_{2}\right)$ concentration in the atmosphere has increased considerably. $\mathrm{CO}_{2}$ has been classified as the primary anthropogenic greenhouse gas. Further, the sources of $\mathrm{CO}_{2}$ emission have been found from combustion of fossil fuels and industrial processes. ${ }^{1}$

Amongst all the $\mathrm{CO}_{2}$ separation technologies, membrane separation is a feasible carbon capture and storage technology for removal of $\mathrm{CO}_{2}$. Therefore, membrane technology has become attractive to industries as it is environmentally friendly, easy to scale up and energy efficient. ${ }^{2}$ Hence, there are many types of polymers such as cellulose ester, cellulose nitrate, cellulose propionate, methylcellulose, ethyl cellulose, hydroxypropyl methyl cellulose, fluorinated cellulose acetate and cellulose acetate butyrate (CAB). ${ }^{3}$ Among these polymers, $\mathrm{CAB}$ was selected as the polymer material for membrane due to its outstanding characteristics of great film forming properties, and better thermal and chemical stability compared with cellulose acetate materials, which have a bulky functional group. ${ }^{4}$ In addition, the butyryl and acetyl groups within the $\mathrm{CAB}$ polymer enlarges the capacity of the cellulose chain membrane causing high $\mathrm{CO}_{2}$ solubility in $\mathrm{CAB} .{ }^{5}$ However, there is a limitation of the polymeric membrane, which affects the separation performance of the membrane. This limitation is the trade-off relationship between gas permeability and selectivity, whereby a polymer with high selectivity has low permeability and vice versa. ${ }^{6}$

To overcome this issue, one of the methods to enhance the separation performance of the polymeric membrane is polymeric blending. According to Mukhtar et al., the polysulfone/polyetherimide (PSF/PEI) blend membrane improved the $\mathrm{CO}_{2}$ /methane $\left(\mathrm{CH}_{4}\right)$ selectivity over pure PSF membrane. ${ }^{7}$ The higher PEI concentration led to decrease in $\mathrm{CO}_{2}$ and $\mathrm{CH}_{4}$ permeability and increase in $\mathrm{CO}_{2} / \mathrm{CH}_{4}$ selectivity due to rigidity of PEI chains. Additionally, polymer concentration plays a critical role for membrane fabrication. According to Alavi et al., a lower polydimethylsiloxane (PDMS) concentration formed a thin selective skin layer of the PDMS membrane. ${ }^{8}$ It resulted in higher $\mathrm{CO}_{2}, \mathrm{~N}_{2}$ and $\mathrm{CH}_{4}$ permeance as the $\mathrm{CO}_{2}(3457.0 \mathrm{GPU}), \mathrm{N}_{2}(145.2 \mathrm{GPU})$ and $\mathrm{CH}_{4}(3457.2 \mathrm{GPU})$ gases were allowed to pass through the PDMS membrane. The higher $\mathrm{CO}_{2} / \mathrm{N}_{2}(23.8)$ and $\mathrm{CO}_{2} /$ $\mathrm{CH}_{4}$ (8.2) selectivity was due to more $\mathrm{CO}_{2}$ gases permeating through the PDMS membrane as compared to the $\mathrm{N}_{2}$ and $\mathrm{CH}_{4}{ }^{8}$

The aim of the present work was to develop a $\mathrm{CAB}$ membrane by blending two different molecular weights of 70000 and 65000 in order to improve the $\mathrm{CO}_{2} / \mathrm{N}_{2}$ selectivity. Therefore, two molecular weights of $\mathrm{CAB}$ polymer were 
chosen. Up to date, there has been no report on synthesising this $\mathrm{CAB}$ blend membrane by blending different ratios of the polar acetyl group of $28-31 \mathrm{wt} \%$ and $12-15 \mathrm{wt} \%$ for $\mathrm{CAB}$ molecular weights of 65000 and 70000 , respectively. Besides, the effect of polymer concentration and solvent exchange drying time on the $\mathrm{CAB}$ membrane structure was evaluated in this study. Polymer concentration has a large impact on membrane morphology and membrane separation performance. It causes the formation of thicker membrane that decreases gas selectivity and gas permeance when the polymer concentration increases significantly. The separation performance of the $\mathrm{CAB}$ polymer blending membrane and the pure $\mathrm{CAB}$ membrane were compared by calculating the $\mathrm{CO}_{2}$, and $\mathrm{N}_{2}$ permeances and $\mathrm{CO}_{2} / \mathrm{N}_{2}$ selectivity.

\section{EXPERIMENTAL}

\subsection{Materials}

The $\mathrm{CAB}$ polymer of molecular weight 70000 with an acetyl group of $12-15 \mathrm{wt} \%$ and the $\mathrm{CAB}$ polymer of molecular weight 65000 with acetyl group of $28-31 \mathrm{wt} \%$ were purchased from Sigma-Aldrich (Malaysia). The chemical solutions used for membrane fabrication were chloroform, isopropyl alcohol (99.6\%) and n-hexane (99.8\%). These which were purchased from Merck (Malaysia).

\subsection{Fabrication of CAB Membrane}

The $\mathrm{CAB}$ membrane was fabricated using the wet-phase inversion method. The casting solution contained $4 \mathrm{wt} \% \mathrm{CAB}$ (70000 and 65000) and $96 \mathrm{wt} \%$ chloroform. The solution was stirred for $24 \mathrm{~h}$ to ensure that the $\mathrm{CAB}$ polymer dissolved completely. Then, the dope solution was sonicated by ultrasonic degasser to remove the air bubbles in the solution. The dope solution was cast with membrane film of uniform thickness of $250 \mu \mathrm{m}$ by using an automatic film applicator. The membrane film was then allowed 5 min solvent evaporation time to evaporate the remaining solvent. The membrane was then immersed into distilled water for $24 \mathrm{~h}$ to remove the excess solvent from the membrane. In order to maintain the membrane structure, the membrane film was immersed in isopropyl alcohol for $1 \mathrm{~h}$ to replace the water within the membrane. Subsequently, the membrane film was immersed in $\mathrm{n}$-hexane for another $1 \mathrm{~h}$ as this solvent is less volatile and minimises the capillary force within the membrane. Thus, the membrane structure was maintained. The fabricated CAB membrane was placed between two glass plates filled with filter papers for $24 \mathrm{~h}$ to remove the remaining volatile liquid on the membrane film. The fabricated $\mathrm{CAB}$ membrane was stored before use. ${ }^{9}$ 


\subsubsection{Effect of CAB polymer concentration of different molecular weights}

The other $\mathrm{CAB}$ membrane was fabricated based on the membrane fabrication method. Different molecular weight contents of $\mathrm{CAB}$ polymer were used on $\mathrm{CAB}$ membrane as tabulated in Table 1.

Table 1: Preparation of CAB membrane at different content of molecular weight.

\begin{tabular}{lcccccc}
\hline $\begin{array}{l}\text { Sample } \\
\text { description }\end{array}$ & $\begin{array}{c}\mathrm{CAB} \\
(\mathrm{wt} \%)\end{array}$ & $\begin{array}{c}\mathrm{CAB} \\
(\mathrm{molecular} \\
\text { weight } \\
70000)\end{array}$ & $\begin{array}{c}\mathrm{CAB} \\
(\text { molecular } \\
\text { weight }\end{array}$ & $\begin{array}{c}\text { Casting } \\
\text { thickness } \\
(\mu \mathrm{m})\end{array}$ & $\begin{array}{c}\text { Hexane } \\
\text { exchange } \\
\text { drying time } \\
(\mathrm{min})\end{array}$ & $\begin{array}{c}\text { Isopropyl alcohol } \\
\text { exchange drying } \\
\text { time }(\mathrm{min})\end{array}$ \\
\hline M1 & 4 & 0.75 & 0.25 & 250 & 60 & 60 \\
M2 & 4 & 0.6 & 0.4 & 250 & 60 & 60 \\
M3 & 4 & 0.4 & 0.6 & 250 & 60 & 60 \\
M4 & 4 & 0.3 & 0.7 & 250 & 60 & 60 \\
\hline
\end{tabular}

\subsection{Membrane Characterisation}

\subsubsection{SEM}

The scanning electron microscope (SEM) was used to acquire visual information of membrane surface morphology and cross-sectional structure of the membrane. The membrane sample was cooled in the freezer at about $-80^{\circ} \mathrm{C}$ for $24 \mathrm{~h}$ so that the membrane was easy to cut. The membrane sample was coated with a thin film of gold and platinum to improve the contrast and prevent the deterioration of image information. ${ }^{10}$ The membrane thickness was determined by using the ImageJ software. Fewer results were collected for consistency.

\subsubsection{ATR-FTIR spectroscopy}

The attenuated total reflectance-Fourier transform infrared (ATR-FTIR) spectroscopy was used to analyse the functional group and bond of membrane. The range of ATR-FTIR was from $400 \mathrm{~cm}^{-1}$ to $4000 \mathrm{~cm}^{-1}$. The radiation beam was absorbed by the sample and the reflected radiation beam was collected by the detector. The information for room condition was collected first to obtain the spectra wave number of samples. ${ }^{11}$ Fewer results were again collected for consistency. 


\subsection{Membrane Separation Performance Test}

The gas permeation test was performed to evaluate the separation performance of the $\mathrm{CAB}$ membrane. The gas permeation test was conducted based on previous published works.

where,

$$
\begin{aligned}
& \frac{\mathrm{P}}{\ell}=\frac{\mathrm{Q}}{\mathrm{A} \Delta p} \\
& \alpha_{\mathrm{CO}_{2} / \mathrm{N}^{2}}=\frac{\left(\frac{p}{\ell}\right)_{\mathrm{CO}_{2}}}{\left(\frac{p}{\ell}\right)_{\mathrm{N}_{2}}}
\end{aligned}
$$

$\frac{\mathrm{P}}{\ell}=$ gas permeance (GPU)

$\ell=$ membrane thickness $(\mathrm{cm})$

$\mathrm{Q}=$ volumetric flow rate $\left(\mathrm{cm}^{3} \mathrm{~s}^{-1}\right)$

$\mathrm{A}=$ effective membrane area $\left(\mathrm{cm}^{3}\right)$

$\Delta p=$ pressure difference across membrane $(\mathrm{cmHg})$

$\alpha=$ gas selectivity

\subsection{Calculation of Average Acetyl Content of CAB Membranes}

According to Sigma-Aldrich, the composition of $\mathrm{CAB}$ with molecular weight of 65000 is $29.5 \mathrm{wt} \%$ acetyl, $17.75 \mathrm{wt} \%$ butyryl and $1.1 \mathrm{wt} \%$ hydroxyl, while the composition of CAB with molecular weight of 70000 is $13.5 \mathrm{wt} \%$ acetyl, $37 \mathrm{wt} \%$ butyryl and $1.7 \mathrm{wt} \%$ hydroxyl. The average acetyl content of blend membrane, which was synthesised from two different ratios of molecular weights was calculated by using the following Equation $3:^{12}$

$$
\mathrm{AAC}=\mathrm{BR}_{70000} \times \mathrm{AC}_{70000}+\mathrm{BR}_{65000} \times \mathrm{AC}_{65000}
$$

where $\mathrm{AAC}=$ average acetyl content $(\%), \mathrm{BR}=$ blending ratio, and $\mathrm{AC}=$ acetyl content $(\%)$. 


\section{RESULTS AND DISCUSSION}

\subsection{Effect of CAB Polymer Concentration at Different Molecular Weights}

The polymer blending at different molecular weights was one of the crucial factors that affected the morphology and gas separation performance of the membrane. ${ }^{13}$ Therefore, $\mathrm{CAB}$ membrane was fabricated using different blend compositions to investigate the effect of polymer blending, which correlated with membrane structure. To have a better understanding on the behaviour of membrane gas transport, SEM analysis was conducted to observe the membrane surface and cross-sectional morphologies of the $\mathrm{CAB}$ membrane, which also controls the gas transport mechanism through the membrane. Figure 1 demonstrates the membrane surface and cross-sectional morphologies for the CAB membranes with molecular weights of 70000 and 65000 blended at different ratios of M1 (0.75:0.25), M2 (0.6:0.4), M3 (0.4:0.6) and M4 (0.3:0.7). Figure 1(a, c, e, g) shows the smooth and defect free surfaces for M1, M2, M3 and M4. This was due to bonding between the hydroxyl groups of the CAB polymer. The hydrogen bonding between the hydroxyl groups caused the polymer chains to become rigid, which restricted the formation of voids in the neighbouring $\mathrm{C}-\mathrm{OH}$ rings, thus resulting in homogeneity on the surface of the membrane. This is shown in Figure 2.

Additionally, ATR-FTIR was used to investigate the intermolecular forces between the functional groups within the CAB membrane. The ATR-FTIR showed that the functional groups within $\mathrm{CAB}$ membrane improved the $\mathrm{CO}_{2}$ solubility. The ATRFTIR spectra for M1, M2, M3 and M4 are demonstrated in Figure 2. Based on the figure, the absorption band at around $2950 \mathrm{~cm}^{-1}$ was attributed to the stretching of the methyl (C-H) group. ${ }^{14}$ Moreover, the band at around $1800 \mathrm{~cm}^{-1}$ was assigned to the carbonyl group vibration of carboxylic $(\mathrm{C}=\mathrm{O})$ group. ${ }^{15}$ Furthermore, the band at $1395 \mathrm{~cm}^{-1}$ represented the hydroxyl $(-\mathrm{OH})$ group and the band at around 1200 $\mathrm{cm}^{-1}$ was referred to as the stretching of the acrylate $(\mathrm{C}-\mathrm{O})$ group. ${ }^{16}$ In addition, the band at $1030 \mathrm{~cm}^{-1}$ was assigned as the stretching of the ether $(\mathrm{C}-\mathrm{O}-\mathrm{C})$ group. ${ }^{17}$

As seen in Figure 2, the polar functional groups in the CAB polymer that affected the gas separation performance were $\mathrm{C}=\mathrm{O}$ group and $\mathrm{O}-\mathrm{H}$ group. ${ }^{18}$ The $\mathrm{C}=\mathrm{O}$ and $\mathrm{O}-\mathrm{H}$ groups had hydrogen bond interaction with $\mathrm{CO}_{2}$ molecules. ${ }^{19}$ Thus, the $\mathrm{C}=\mathrm{O}$ and $\mathrm{O}-\mathrm{H}$ groups interacted with the $\mathrm{CO}_{2}$ gas and increased the $\mathrm{CO}_{2}$ permeance and $\mathrm{CO}_{2} / \mathrm{N}_{2}$ selectivity. Based on Figure 2, M3 had higher absorption band of $\mathrm{O}-\mathrm{H}$, $\mathrm{C}=\mathrm{O}, \mathrm{C}-\mathrm{O}$ and $\mathrm{C}-\mathrm{O}-\mathrm{C}$ groups. This was due to the increase in the content to $60 \%$ of the $\mathrm{CAB}$ with molecular weight of 65000 in the blend. Therefore, M3 contained more $\mathrm{O}-\mathrm{H}, \mathrm{C}=\mathrm{O}, \mathrm{C}-\mathrm{O}$ and $\mathrm{C}-\mathrm{O}-\mathrm{C}$ groups, which when bonded with each other strengthened the intermolecular hydrogen bonding. ${ }^{20}$ 

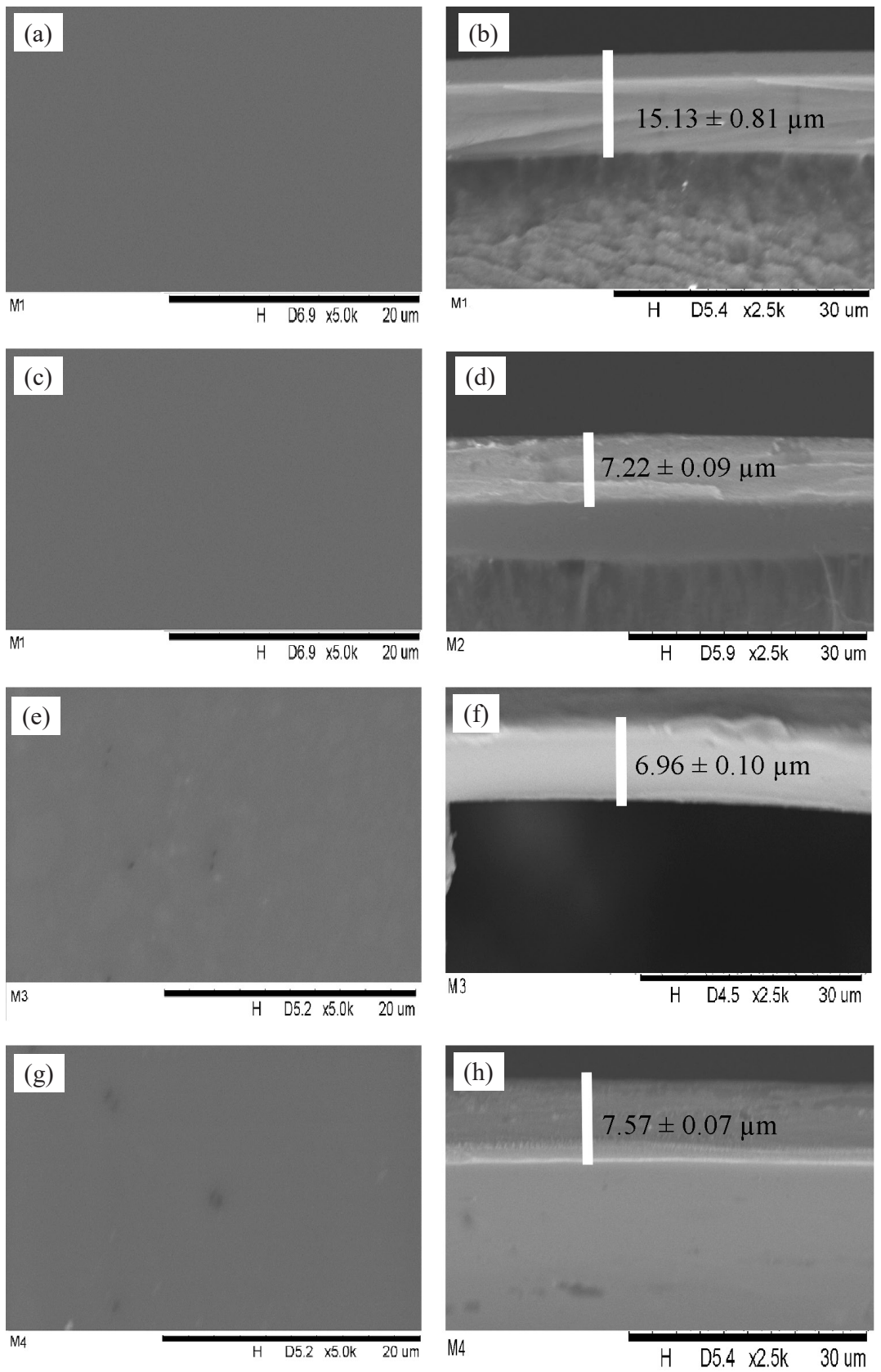

Figure 1: SEM micrographs of surface (a, c, e, g) and cross section (b, d, f, h) for M1, M2, $\mathrm{M} 3$ and $\mathrm{M} 4,4 \mathrm{wt} \% \mathrm{CAB}$ polymer concentration, $250 \mu \mathrm{m}$ casting thickness, 5 min solvent evaporation time, $1 \mathrm{~h}$ isopropyl alcohol and $1 \mathrm{~h}$ hexane solvent exchange drying time. 


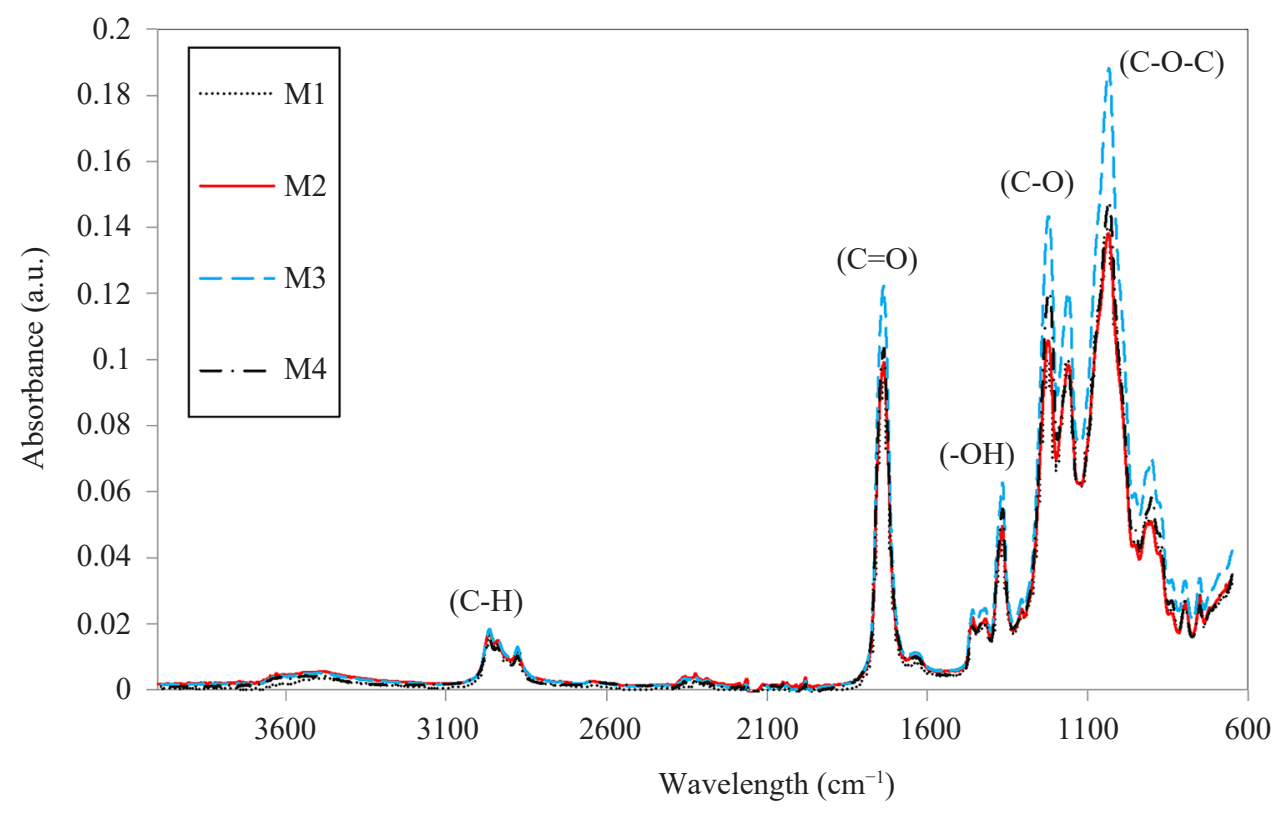

Figure 2: ATR-FTIR for M1, M2, M3 and M4, $4 \mathrm{wt} \%$ CAB polymer concentration, $250 \mu \mathrm{m}$ casting thickness, 5 min solvent evaporation time, $1 \mathrm{~h}$ isopropyl alcohol and $1 \mathrm{~h}$ hexane solvent exchange drying time.

Based on Figure 1(b, d, f, g), the membrane thickness reduced from $15.13 \pm 0.81$ $\mu \mathrm{m}$ for M1 to $6.96 \pm 0.10 \mu \mathrm{m}$ for M3. This was due to the increase in the CAB polymer concentration with molecular weight of 65000 from 0.25 to 0.6 , which strengthened the thermodynamic instability of the dope solution. Moreover, the increment in the polymer concentration increased the solvent diffusivity, which caused more solvent to evaporate from the cast polymer solution resulting in reduced membrane thickness. ${ }^{21}$ Besides that, the membrane thickness of M3 increased from $6.96 \pm 0.10 \mu \mathrm{m}$ to $7.57 \pm 0.07 \mu \mathrm{m}$, as demonstrated in Figure $1(\mathrm{f}$ and $\mathrm{h})$. This was due to the strong interaction between solvent and polymer, which accelerated the aggregation of polymer molecules and formed a thicker membrane. ${ }^{22}$

Based on Figure 3, the $\mathrm{CO}_{2}$ permeance decreased from 129.55 \pm 0.58 GPU for M1 to $6.25 \pm 0.08 \mathrm{GPU}$ for M4. This observation was due to the increased acetyl content within the $\mathrm{CAB}$ membrane, as shown in Table 2. Therefore, the increase in the composition of $\mathrm{CAB}$ with molecular weight of 65000 increased the acetyl content within the $\mathrm{CAB}$ membrane, resulting in more acetyl groups bonding with each other. This caused the polymer chain to become more rigid, resulting in the reduction of the chain segment mobility of $\mathrm{CAB}{ }^{23}$ Moreover, the low polymer 
chain segment mobility of $\mathrm{CAB}$ membrane restricts the diffusion of $\mathrm{CO}_{2}$ gas molecules. ${ }^{24}$ Thus, the $\mathrm{CO}_{2}$ gas molecules took a tortuous path to get through the CAB membrane. ${ }^{25}$

Table 2: Summary of calculated average acetyl content of CAB membrane at different ratios for molecular weights of 70000 and 65000 .

\begin{tabular}{cccc}
\hline Membrane & $\begin{array}{c}\text { Ratio of molecular } \\
\text { weight of } 70000\end{array}$ & $\begin{array}{c}\text { Ratio of molecular } \\
\text { weight of } 65000\end{array}$ & $\begin{array}{c}\text { Calculated average acetyl } \\
\text { content (wt\%) }\end{array}$ \\
\hline M1 & 0.75 & 0.25 & 17.5 \\
M2 & 0.6 & 0.4 & 19.9 \\
M3 & 0.4 & 0.6 & 23.1 \\
M4 & 0.3 & 0.7 & 24.7 \\
\hline
\end{tabular}

The increase in the $\mathrm{CO}_{2}$ permeance of $\mathrm{M} 1$ was due to the membrane structure becoming less dense. This is demonstrated in Figure 1(b). In addition, the formation of the thicker and less dense membrane was due to the weak intermolecular force within the $\mathrm{CAB}$ membrane. As previously described in Figure 2, a possible explanation was that the absorbance band of $\mathrm{O}-\mathrm{H}$ group for $\mathrm{M} 1$, which was prepared by blending the $\mathrm{CAB}$ polymer with molecular weights of 70000 and 65000 at ratio of $0.75: 0.25$, respectively, was at its lowest. Thus, having fewer $\mathrm{O}-\mathrm{H}$ groups resulted in the formation of a weak intermolecular force, which caused the polymer chain apart from each other. ${ }^{26}$ Hence, it was proven that the flow resistance to the membrane decreased causing more $\mathrm{CO}_{2}$ molecules to pass through the membrane. ${ }^{27}$

With reference to Figure 4, the nitrogen $\left(\mathrm{N}_{2}\right)$ permeance reduced significantly from $49.04 \pm 0.61 \mathrm{GPU}$ for M1 to $4.07 \pm 0.02 \mathrm{GPU}$ for M4. The reduction in $\mathrm{N}_{2}$ permeance was due to the strong intermolecular hydrogen bonding within the $\mathrm{CAB}$ polymer matrix (Figure 2). Moreover, the strong intermolecular hydrogen bonding was formed by the increased interaction between $\mathrm{O}-\mathrm{H}$ and $\mathrm{C}=\mathrm{O}$ groups. Besides that, $\mathrm{N}_{2}$ is a non-polar molecule and interacts less with hydrogen bonding in the CAB. ${ }^{28}$ Thus, the $\mathrm{N}_{2}$ gas has lower solubility than $\mathrm{CO}_{2}$ in the polymer structure of $\mathrm{CAB}$ and shows lower gas permeances than $\mathrm{CO}_{2} \cdot{ }^{29}$ The dramatic increment in the $\mathrm{N}_{2}$ permeance of M1 was due to the weak intermolecular hydrogen bonding within the $\mathrm{CAB}$ membrane, as demonstrated in Figure 2. This result occurred because less $\mathrm{O}-\mathrm{H}$ and $\mathrm{C}=\mathrm{O}$ groups interacted with each other to form hydrogen bonding. ${ }^{30}$ Therefore, the weak intermolecular hydrogen bonding reduced density, which led to an increase in chain flexibility and mobility in the CAB membrane. Thus, low packing chain density of the $\mathrm{CAB}$ membrane caused more $\mathrm{N}_{2}$ gases to pass through the membrane, which increased the $\mathrm{N}_{2}$ permeance. ${ }^{31}$ 


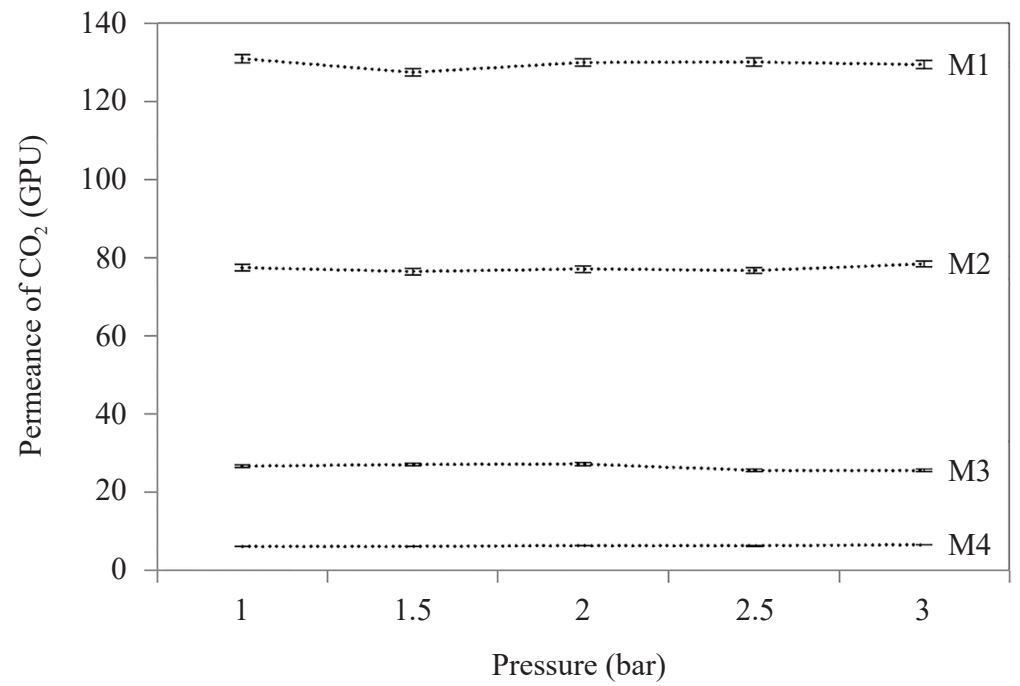

Figure 3: $\mathrm{CO}_{2}$ permeance for $\mathrm{M} 1, \mathrm{M} 2, \mathrm{M} 3$ and $\mathrm{M} 4,4 \mathrm{wt} \% \mathrm{CAB}$ polymer concentration, $250 \mu \mathrm{m}$ casting thickness, 5 min solvent evaporation time, $1 \mathrm{~h}$ isopropyl alcohol and $1 \mathrm{~h}$ hexane solvent exchange drying time.

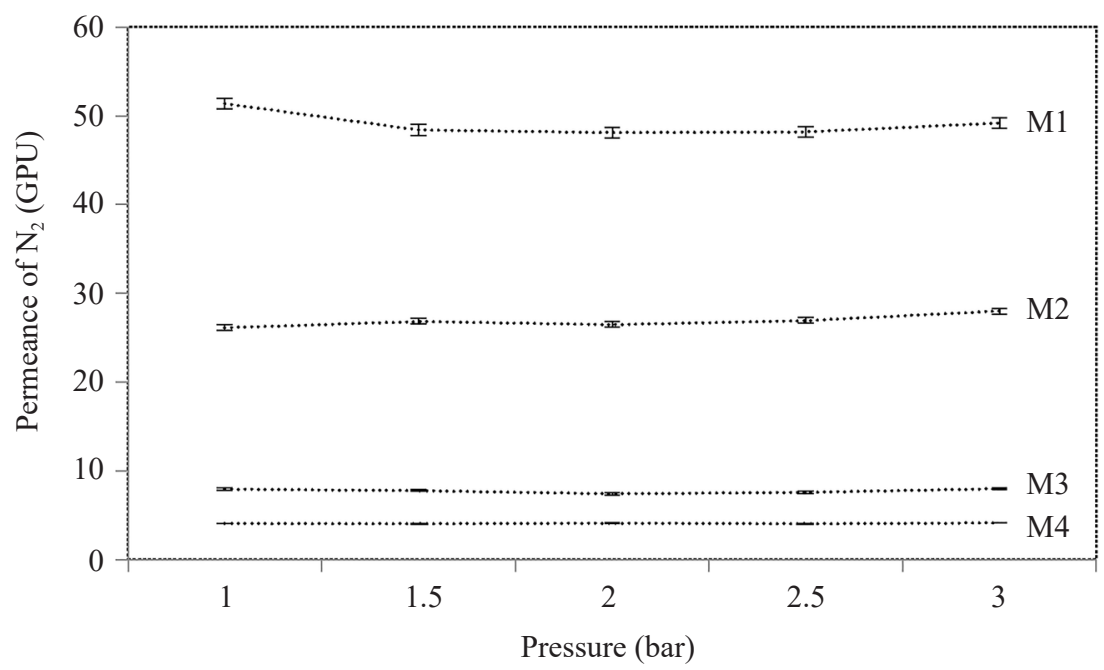

Figure 4: $\mathrm{N}_{2}$ permeance for M1, M2, M3 and M4, $4 \mathrm{wt} \%$ CAB polymer concentration, $250 \mu \mathrm{m}$ casting thickness, 5 min solvent evaporation time, $1 \mathrm{~h}$ isopropyl alcohol and $1 \mathrm{~h}$ hexane solvent exchange drying time. 
Based on Figure 5, the $\mathrm{CO}_{2} / \mathrm{N}_{2}$ selectivity increased significantly from $2.64 \pm 0.03$ for $\mathrm{M} 1$ to $3.41 \pm 0.08$ for $\mathrm{M} 3$. The significant increase in $\mathrm{CO}_{2} / \mathrm{N}_{2}$ selectivity was due to the increase in the polar functional groups $(\mathrm{C}=\mathrm{O}$ and $\mathrm{O}-\mathrm{H})$, which improved the polarity of the $\mathrm{CAB}$ membrane, resulting in favourable conditions for the $\mathrm{CO}_{2}$ solubility. ${ }^{32}$ Besides that, the absorbance bands of $\mathrm{O}-\mathrm{H}$ and $\mathrm{C}=\mathrm{O}$ groups for $\mathrm{M} 3$ were the highest, as demonstrated in Figure 2. M3 was prepared by blending the $\mathrm{CAB}$ polymer with molecular weights of 70000 and 65000 in the ratio of $0.4: 0.6$, respectively. Thus, with the help of strong intermolecular hydrogen bonding, the $\mathrm{CO}_{2}$ solubility of $\mathrm{M} 3$ was enhanced. In addition, the $\mathrm{CO}_{2}$ solubility was promoted because the $\mathrm{CO}_{2}$ served as an electron acceptor and interacted with the polar functional groups in the $\mathrm{CAB}$ polymer. ${ }^{33}$ This increased the interaction between the polar functional groups and $\mathrm{CO}_{2}$, which caused high $\mathrm{CO}_{2}$ affinity in the $\mathrm{CAB}$ polymer than for $\mathrm{N}_{2} \cdot{ }^{34}$ Hence, both the $\mathrm{O}-\mathrm{H}$ and $\mathrm{C}=\mathrm{O}$ groups have strong attraction for $\mathrm{CO}_{2}$, which increased the $\mathrm{CO}_{2}$ permeance and improved the $\mathrm{CO}_{2} / \mathrm{N}_{2}$ selectivity. In addition, when the pressure increased from 2 bars to 3 bars, the $\mathrm{CO}_{2} / \mathrm{N}_{2}$ selectivity of M3 decreased slightly. This might be due to more $\mathrm{N}_{2}$ gases passing through the membrane resulting in a slight increase in the $\mathrm{N}_{2}$ permeance (Figure 4) and decrease in the $\mathrm{CO}_{2} / \mathrm{N}_{2}$ selectivity. However, the $\mathrm{CO}_{2} / \mathrm{N}_{2}$ selectivity decreased from $3.42 \pm$ 0.08 (M3) to $1.54 \pm 0.01$ (M4). This result most likely occurred due to the structure of the dense membrane $(7.57 \pm 0.07 \mu \mathrm{m})$, as demonstrated in Figure 1(h). The formation of dense membrane was due to the strong interaction between solvent and polymer that decreased the dissolving capability of solvent for polymer. In addition, it caused the polymer molecules aggregation through chain entanglement and increased the membrane thickness. ${ }^{35}$ Therefore, the dense membrane structure could have contributed to the reduced $\mathrm{CO}_{2}$ and $\mathrm{N}_{2}$ permeances and decreased $\mathrm{CO}_{2} /$ $\mathrm{N}_{2}$ selectivity. Hence, the thicker dense CAB membrane restricted the diffusion of the $\mathrm{CO}_{2}$ and $\mathrm{N}_{2}$ gases. ${ }^{36}$

The effect of $\mathrm{CAB}$ polymer concentration at different molecular weights for separation of $\mathrm{CO}_{2} / \mathrm{N}_{2}$ is summarised in Figure 6. Based on the figure, the M3 membrane proved to have the highest $\mathrm{CO}_{2} / \mathrm{N}_{2}$ selectivity $(3.41 \pm 0.08)$ result amongst the others (M1, M2 and M4). Therefore, an increase in the content of $\mathrm{CAB}$ with molecular weight of 65000 caused the formation of a much thinner and denser membrane, which improved the separation performance. On the other hand, the $\mathrm{M} 1$ membrane had the highest $\mathrm{CO}_{2}(129.55 \pm 0.58 \mathrm{GPU})$ and $\mathrm{N}_{2}$ permeances (49.04 $\pm 0.61 \mathrm{GPU})$. Hence, a low content of $\mathrm{CAB}$ with molecular weight of 65000 caused the membrane to become less dense, which led to more gas permeating through it. The effect of polymer concentration and blend composition affected the membrane morphology and membrane separation performance. 


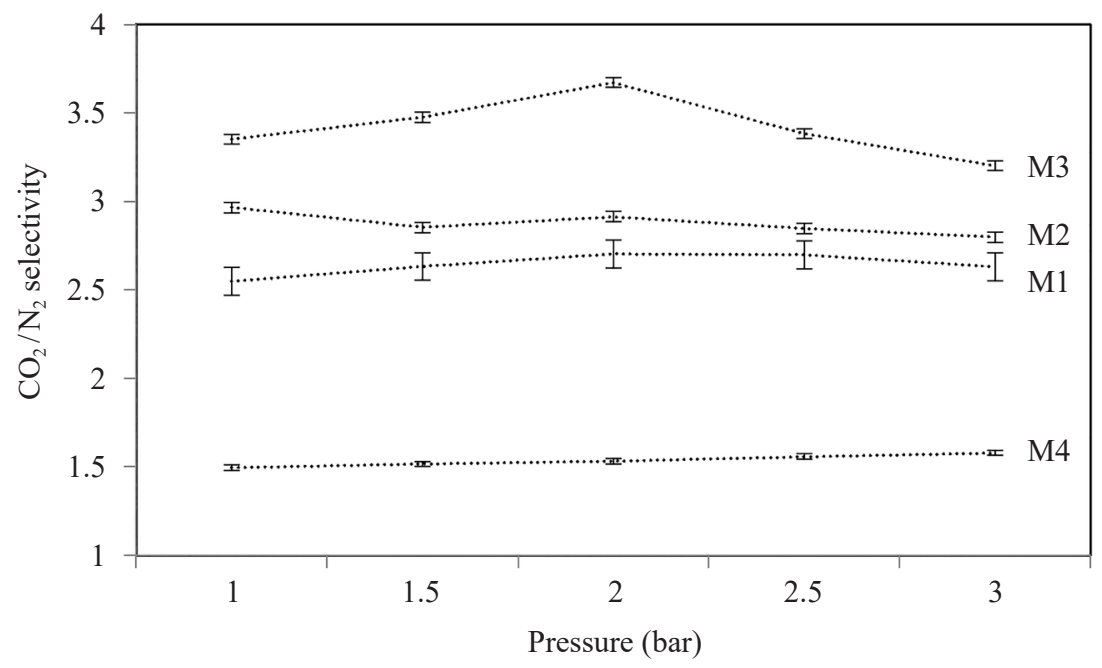

Figure 5: Ideal selectivity of $\mathrm{CO}_{2} / \mathrm{N}_{2}$ for $\mathrm{M} 1, \mathrm{M} 2, \mathrm{M} 3$ and $\mathrm{M} 4,4 \mathrm{wt} \% \mathrm{CAB}$ polymer concentration, $250 \mu \mathrm{m}$ casting thickness, $5 \mathrm{~min}$ solvent evaporation time, $1 \mathrm{~h}$ isopropyl alcohol and $1 \mathrm{~h}$ hexane solvent exchange drying time.

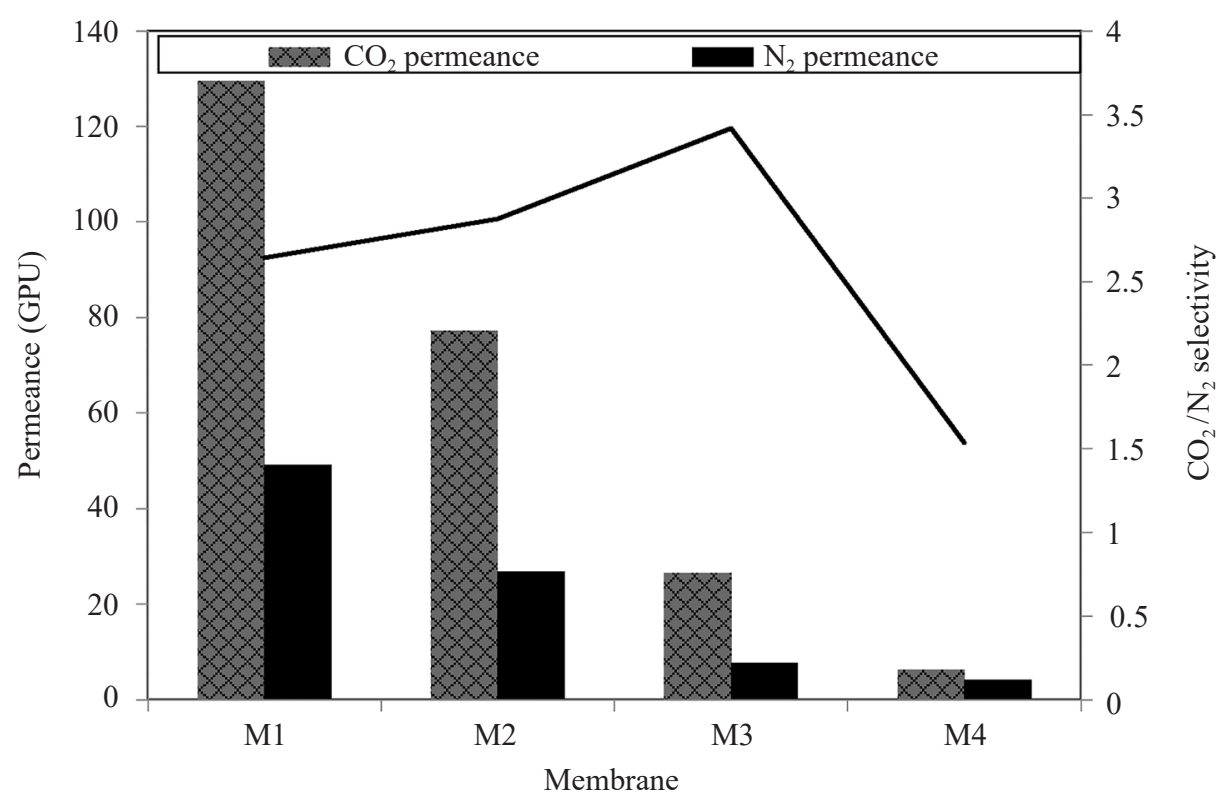

Figure 6: Summary of $\mathrm{CO}_{2} / \mathrm{N}_{2}$ permeation properties for $\mathrm{M} 1, \mathrm{M} 2, \mathrm{M} 3$ and $\mathrm{M} 4$, $4 \mathrm{wt} \% \mathrm{CAB}$ polymer concentration, $250 \mu \mathrm{m}$ casting thickness, $5 \mathrm{~min}$ solvent evaporation time, $1 \mathrm{~h}$ isopropyl alcohol and $1 \mathrm{~h}$ hexane solvent exchange drying time. 
In conclusion, the present work was compared to other research works, which synthesised the $\mathrm{CAB}$ membrane with molecular weight of 70000 , as summarised in Table 3. Based on gas separation performance, the M3 membrane obtained the highest $\mathrm{CO}_{2} / \mathrm{N}_{2}$ selectivity (3.42) in the present work as compared to Lee et al. ${ }^{9}$ However, in comparison, $\mathrm{M} 3$ obtained lower $\mathrm{CO}_{2}$ and $\mathrm{N}_{2}$ permeances in this work. This was due to lower gas diffusivity of the denser membrane and therefore less $\mathrm{CO}_{2}$ and $\mathrm{N}_{2}$ gases diffused through the membrane. ${ }^{37}$ These findings confirmed that the blending of $\mathrm{CAB}$ polymer at different molecular weights improved the membrane morphology and enhanced the $\mathrm{CO}_{2} / \mathrm{N}_{2}$ selectivity of the $\mathrm{CAB}$ membrane. In the future, it is expected that the permeance of $\mathrm{CO}_{2}$ and $\mathrm{N}_{2}$ performance of this newly $\mathrm{CAB}$ membrane will be further enhanced by embedding inorganic fillers within the membrane structure.

Table 3: Summary of $\mathrm{CO}_{2} / \mathrm{N}_{2}$ permeation properties achieved from present work compared to other research study.

\begin{tabular}{lcccccc}
\hline References & Polymer & $\begin{array}{c}\text { Molecular } \\
\text { weight } \\
70000\end{array}$ & $\begin{array}{c}\text { Molecular } \\
\text { weight } \\
65000\end{array}$ & $\mathrm{P}_{\mathrm{CO}_{2}}$ & $\mathrm{P}_{\mathrm{N}_{2}}$ & $\alpha_{\mathrm{CO}_{2} / \mathrm{N}_{2}}$ \\
\hline Present work & $\mathrm{CAB}$ & 0.4 & 0.6 & $26.39 \mathrm{GPU}$ & $7.730 \mathrm{GPU}$ & 3.42 \\
Lee et al. ${ }^{9}$ & $\mathrm{CAB}$ & 1 & 0 & $120.19 \mathrm{GPU}$ & $37.91 \mathrm{GPU}$ & 3.17 \\
\hline
\end{tabular}

\section{CONCLUSION}

The $\mathrm{CAB}$ membrane was developed by blending two different molecular weights, i.e., 70000 and 65000 . In this study, polymer concentration was investigated. Therefore, the membrane with molecular weights of 70000 and 65000 blended in the ratio of 0.4:0.6 resulted in the formation of a thinner dense membrane. Moreover, the thinner membrane showed the highest gas selectivity (3.42) due to the denser membrane structure and strong intermolecular hydrogen bonding, which improved the $\mathrm{CO}_{2}$ solubility. The high gas permeance and high $\mathrm{CO}_{2} / \mathrm{N}_{2}$ selectivity was due to lower collapse of membrane structure. The results from this study showed that the $\mathrm{CAB}$ membrane with molecular weights of 70000 and 65000 blended in the ratio of $0.4: 0.6$, with $4 \mathrm{wt} \%$ of $\mathrm{CAB}$ polymer concentration had the best $\mathrm{CO}_{2} / \mathrm{N}_{2}$ separation performance. 


\section{ACKNOWLEDGEMENTS}

The authors would like to acknowledge the Ministry of Higher Education Malaysia (MOHE) for providing the Fundamental Research Grant Scheme (FRGS) (ref. no. FRGS/1/2015/TK02/CURTIN/03/1) and Cost Centre 001048. The authors would also like to thank the Long-term Research Grant Scheme (LRGS), Universiti Sains Malaysia (account no. 304/PJKIMIA/6050296/U124) and Curtin Cost Centre 001047.

\section{REFERENCES}

1. Graven, $\mathrm{H}$. et al. (2018). Assessing fossil fuel $\mathrm{CO}_{2}$ emissions in California using atmospheric observations and models. Environ. Res. Lett., 13(6), 065007. https://doi.org/10.1088/1748-9326/aabd43

2. Ma, J., Ping, D. \& Dong, X. (2017). Recent developments of graphene oxidebased membranes: A review. Membr., 7(3), 1-29. https://doi.org/10.3390/ membranes 7030052

3. Scholes, C. A., Stevens, G. W. \& Kentish, S. E. (2012). Membrane gas separation applications in natural gas processing. Fuel, 96, 15-28. https://doi.org/10.1016/j. fuel.2011.12.074

4. Han, G., de Wit, J. S. \& Chung, T.-S. (2015). Water reclamation from emulsified oily wastewater via effective forward osmosis hollow fiber membranes under the PRO mode. Water Res., 81, 54-63. https://doi.org/10.1016/j.watres.2015.05.048

5. Seymour, R. W., Weinhold, S. \& Haynes, S. K. (1979). Mechanical and dielectric relaxation in cellulose esters. J. Macromol. Sci. B, 16(3), 337-353. https://doi. org $/ 10.1080 / 00222347908212300$

6. Park, H. et al. (2017). Maximizing the right stuff: The trade-off between membrane permeability and selectivity. Sci., 356(6343), 1138-1148. https://doi.org/10.1126/ science.aab0530

7. Mukhtar, $\mathrm{H}$. et al. (2016). Polymer blend membranes for $\mathrm{CO}_{2}$ separation from natural gas. IOP Conf. Ser. Earth Environ. Sci., 36(1), 012016. https://doi. org/10.1088/1755-1315/36/1/012016

8. Alavi, S. et al. (2017). Preparation and characterization of PDMS/zeolite 4A/PAN mixed matrix thin film composite membrane for $\mathrm{CO}_{2} / \mathrm{N}_{2}$ and $\mathrm{CO}_{2} / \mathrm{CH}_{4}$ separations. Res. Chem. Intermed., 43(5), 2959-2984. https://doi.org/10.1007/s11164-0162806-2

9. Lee, R. J. et al. (2017). Improvement of $\mathrm{CO}_{2} / \mathrm{N}_{2}$ separation performance by polymer matrix cellulose acetate butyrate. IOP Conf. Ser. Mater. Sci. Eng., 206(1), 012072. https://doi.org/10.1088/1757-899X/206/1/012072

10. Tylkowski, B. \& Tsibranska, I. (2014). Overview of main techniques used for membrane characterization. J. Chem. Technol. Metal., 50(1), 3-12.

11. Barbes, L., Radulescu, C. \& Stihi, C. (2014). ATR-FTIR spectrometry characterisation of polymeric materials. Rom. Rep. Phys., 66(3), 765-777. 
12. Ferraz, A. et al. (2000). Estimating the chemical composition of biodegraded pine and eucalyptus wood by DRIFT spectroscopy and multivariate analysis. Bioresour. Technol., 74(3), 201-212. https://doi.org/10.1016/S0960-8524(00)00024-9

13. Mushtaq, A., Mukhtar, H. \& Shariff, A. M. (2013). Blending behavior of polysulfone, polyvinyl acetate and amines in dimethyl acetamide solvent. J. Sci. Eng. Technol., 7(8), 1634-1641.

14. Lavorgna, M. et al. (2012). Silanization and silica enrichment of multiwalled carbon nanotubes: Synergistic effects on the thermal-mechanical properties of epoxy nanocomposites. Eur. Polym. J., 49(2), 428-438. https://doi.org/10.1016/j. eurpolymj.2012.10.003

15. Suttiwijitpukdee, N. et al. (2011). Intermolecular interactions and crystallization behaviors of biodegradable polymer blends between poly (3-hydroxybutyrate) and cellulose acetate butyrate studied by DSC, FT-IR, and WAXD. Polym., 52(2), 461-471. https://doi.org/10.1016/j.polymer.2010.11.021

16. Del Valle, E. M. M. (2004). Cyclodextrins and their uses: A review. Process Biochem., 39(9), 1033-1046. https://doi.org/10.1016/S0032-9592(03)00258-9

17. Lou, Y. et al. (2014). A facile way to prepare ceramic-supported graphene oxide composite membrane via silane-graft modification. Appl. Surf. Sci., 307, 631-637. https://doi.org/10.1016/j.apsusc.2014.04.088

18. Shan, M. et al. (2012). Influence of chemical functionalization on the $\mathrm{CO}_{2} / \mathrm{N}_{2}$ separation performance of porous graphene membranes. Nanosc., 4(17), 54775482. https://doi.org/10.1039/c2nr31402a

19. Xing, W. et al. (2014). Oxygen-containing functional group-facilitated $\mathrm{CO}_{2}$ capture by carbide-derived carbons. Nanosc. Res. Lett., 9(1), 1-8. https://doi. org/10.1186/1556-276X-9-189

20. El-Sakhawy, M. et al. (2018). Preparation and infrared study of cellulose based amphiphilic materials. Cell. Chem. Technol., 52(3-4), 193-200.

21. Ikhsan, D. et al. (2017). Effect of combination dope composition and evaporation time on the separation performance of cellulose acetate membrane for demak brackish water treatment. MATEC Web Conf., 101, 01004. https://doi.org/10.1051/ matecconf/201710101004

22. Mustaffar, Ismail, A. \& Illias, R. (2018). Study on the effect of polymer concentration on hollow fiber ultrafiltration membrane performance and morphology. Unpublished paper, Faculty of Chemical and Natural Engineering, Universiti Teknologi Malaysia, 1-12.

23. Marais, S. et al. (2004). Transport of water and gases through EVA/PVC blend films-permeation and DSC investigations. Polym. Test., 23(4), 475-486. https://doi.org/10.1016/j.polymertesting.2003.09.009

24. Zhang, H. \& Cloud, A. (2006). The permeability characteristics of silicone rubber. Unpublished technical paper, Arlon Silicone Technologies Division, Delaware.

25. Liu, Y. et al. (2014). Enhanced $\mathrm{CO}_{2}$ permeability of membranes by incorporating polyzwitterion@CNT composite particles into polyimide matrix. ACS Appl. Mater. Interf., 6(15), 13051-13060. https://doi.org/10.1021/am502936x 
26. Krishnamurthi, P.P., Ramalingam, H. B. \& Raju, K. P. (2015). FTIR studies of hydrogen bonding interaction between the hydroxyl and carbonyl liquids. Adv. Appl. Sci. Res., 6(12), 44-52.

27. Ngogu, N. \& Gobina, E. (2015). Gas permeation behavior of single and mixed gas components using an asymmetric ceramic membrane. Int. J. Mater. Metal. Eng., 9(6), 689-693. https://doi.org/10.5281/zenodo.1107233

28. Marsh, K. N., Boxall, J. A. \& Lichtenthaler, R. (2004). Room temperature ionic liquids and their mixtures-A review. Fluid Phase Equilib., 219(1), 93-98. https://doi.org/10.1016/j.fluid.2004.02.003

29. Lee, R. J. et al. (2018). Incorporation of functionalized multi-walled carbon nanotubes (MWCNTs) into cellulose acetate butyrate (CAB) polymeric matrix to improve the $\mathrm{CO}_{2} / \mathrm{N}_{2}$ separation. Process. Saf. Environ., 117, 159-167. https://doi.org/10.1016/j.psep.2018.04.021

30. Powell, C. E. \& Qiao, G. G. (2006). Polymeric $\mathrm{CO}_{2} / \mathrm{N}_{2}$ gas separation membranes for the capture of carbon dioxide from power plant flue gases. J. Membr. Sci., 279 (1), 1-49. https://doi.org/10.1016/j.memsci.2005.12.062

31. Jie, X. et al. (2004). Gas permeation performance of cellulose hollow fiber membranes made from the cellulose/ $\mathrm{N}$-methylmorpholine- $\mathrm{N}$-oxide/ $\mathrm{H}_{2} \mathrm{O}$ system. J. Appl. Polym. Sci., 91(3), 1873-1880. https://doi.org/10.1002/app.2385

32. Mazinani, S. et al. (2018). A ground breaking polymer blend for $\mathrm{CO}_{2} / \mathrm{N}_{2}$ separation. J. CO 2 Utiliz., 27, 536-546. https://doi.org/10.1016/j.jcou.2018.08.024

33. Yuan, Y. \& Teja, A. S. (2011). Quantification of specific interactions between $\mathrm{CO}_{2}$ and the carbonyl group in polymers via ATR-FTIR measurements. J. Superc. Fluids, 56(2), 208-212. https://doi.org/10.1016/j.supflu.2010.12.010

34. Kunthadong, P. et al. (2015). Biodegradable plasticized blends of poly(l-lactide) and cellulose acetate butyrate: From blend preparation to biodegradability in real composting conditions. J. Polym. Environ., 23(1), 107-113. https://doi. org/10.1007/s10924-014-0671-x

35. Kimmerle, K. \& Strathmann, H. (1990). Analysis of the structure-determining process of phase inversion membranes. Desalin., 79(2-3), 283-302. https://doi. org/10.1016/0011-9164(90)85012-y

36. Tan, P. C. et al. (2016). Correlation between polymer packing and gas transport properties for $\mathrm{CO}_{2} / \mathrm{N}_{2}$ separation in glassy fluorinated polyimide membrane. J. Eng. Sci. Technol. Rev., 11(7), 935-946.

37. Fu, Y. et al. (2018). Ultra-thin enzymatic liquid membrane for CO separation and capture. Nat. Comm., 9(1), 990-990. https://doi.org/10.1038/s41467-018-03285-x 